\title{
Zero-order Delivery of Alfuzosin Hydrochloride with Hydrophilic Polymers
}

\author{
Jun-Bom Park, Chang-Hwan Hwang, Hyung-Gon Noh, Yu-Byeong Chae, \\ Jun-Woo Song and Chin-Yang Kang ${ }^{\dagger}$ \\ College of Pharmacy, Sahm Yook University, Seoul 139-742, Korea \\ (Received July 21, 2010 • Revised October 11, 2010 • Accepted October 12, 2010)
}

\begin{abstract}
Manufacturing a multi-layered tablet such as Xatral $\mathrm{XL}^{\circledR}$ is more complex and expensive than monolayered tablets, but mono-layered tablets may have less favorable release properties depending on the pharmacodynamics and pharmacokinetics of the active ingredient. We therefore sought to develop a monolayer tablet with a similar dissolution profile to the commercial alfuzosin sustained-release triple layered tablet (Xatral XL ${ }^{\circledR}$ ). We prepared four different mono-layered alfuzosin tablets with different concentrations of hydroxypropyl methycellulose and PVP K-90. Fomulation III with alfuzosion/ mg-stearate/ HPMC/ PVP K-90 (10/5/110/95 mg/tab) has a similar dissolution rate to Xatral XL ${ }^{\circledR}$, with a similarity factor score of 81.4. However, the swelling and erosion rates of the two formulations were different, and NIR analysis showed differences in the mechanisms of drug release. Thus, although formulation III and Xatral XL ${ }^{\circledR}$ show similar dissolution rates, the mechanisms of drug release are different.
\end{abstract}

Key words - Alfuzosin $\mathrm{HCl}$, Xatral XL ${ }^{\circledR}$, HPMC, PVP, Mono-layered tablet

Alfuzosin $\mathrm{HCl}$ is approved for the treatment of benign prostatic hyperplasia and given as $2.5 \mathrm{mg}$ three times a day or as a sustained-release form as $5 \mathrm{mg}$ two times a day. However, the need for repeated administration reduces patient compliance (Jardin et al., 1999; Buzelin et al., 1993; Jardin et al., 1993; Teillac et al., 1992; Jardin et al., 1991). The GEOMATRIX $^{\circledast}$ drug delivery system of sustained-release dosing gives a constant drug release rate and allows for once-a-day dosing. The system uses a triple-layer tablet with a white center layer that contains the active ingredient in an active matrix with two outer yellow layers that can be expanded or eroded to control the hydration and swelling rates of the center layer to give a constant dissolution rate. This drug delivery system produces constant drug dissolution over $18 \mathrm{~h}$ and reduces plasma fluctuations, as well as increasing patient compliance (Maggi et al., 2000).

Despite these advantages, producing these multi-layer tablets is both more complex and more expensive. The Jenn-Chiang Machinery Company, which manufactures the tablets, indicates that multi-layer tablet machines are 3-fold more expensive than single-layer tablet machines, and material loss for multi-layer tablets is also 3-fold higher. Manufacturing costs will be reduced if the same dissolution properties can be achieved with a single-layered tablet (JENN-CHIANG

†Corresponding Author:

Tel : +82-3399-1600, E-mail : kangjy@syu.ac.kr

DOI : 10.4333/KPS.2010.40.5.285
MACHINERY Homepage). We therefore sought to produce sustained-release tablets in a mono-layered drug matrix that produces a constant release of drug substance over $18 \mathrm{~h}$.

\section{Materials and Methods}

\section{Materials}

Alfuzosin $\mathrm{HCl}$ was purchased from Farmak (Olomouc, Czech), tetrahydrofuran and sodium chloride from Kanto chemical (Isehara, Japan), and hydrochloric acid and perchloric acid from Junsei (Tokyo, Japan). Magnesium stearate was supplied by Hwa-il chemical (Seoul, Korea), PVP K-90 from BASF (Seoul, Korea), and HPMC from Shin-etsu (Tokyo, Japan). Xatral $\mathrm{XL}^{\circledR}$ was obtained from Handok (Seoul, Korea), distilled water, ethanol and methanol graded for HPLC from Burdick \& Jackson (Ulsan, Korea). All other materials and reagents were of reagent grade or above.

\section{Tablet manufacturing}

With Alfuzosin $\mathrm{HCl}$ as the active ingredient, and magnesium stearate, HPMC, PVP K-90 as excipients, the tablet was produced with a Single Rotary Tableting machine (Chamunda Pharma, CPM 03-10) (Ahmedabad, India) with direct compression, with formulations summarized in Table I.

\section{In vitro dissolution study}

The dissolution study for tablets containing $10 \mathrm{mg}$ Alfuzosin $\mathrm{HCl}$ was performed using a USP 32 apparatus 2 (paddle), 
Table I. Compositions and Amounts of the Tablets

\begin{tabular}{lcccc}
\hline \hline \multirow{2}{*}{ Formulation } & \multicolumn{4}{c}{ Ingredients } \\
\cline { 2 - 5 } & $\begin{array}{c}\text { Alfuzosin } \\
\mathrm{HCl}\end{array}$ & $\begin{array}{c}\text { Magnesium } \\
\text { stearate }\end{array}$ & HPMC $^{\text {a) }}$ & PVP K-90 \\
\hline Formulation I & $10 \mathrm{mg}$ & $5 \mathrm{mg}$ & $90 \mathrm{mg}$ & $115 \mathrm{mg}$ \\
Formulation II & $10 \mathrm{mg}$ & $5 \mathrm{mg}$ & $100 \mathrm{mg}$ & $105 \mathrm{mg}$ \\
Formulation III & $10 \mathrm{mg}$ & $5 \mathrm{mg}$ & $110 \mathrm{mg}$ & $95 \mathrm{mg}$ \\
Formulation IV & $10 \mathrm{mg}$ & $5 \mathrm{mg}$ & $120 \mathrm{mg}$ & $85 \mathrm{mg}$ \\
\hline
\end{tabular}

a): Hydroxypropylmethylcellulose, b): Polyvinylpyrrolidone

Pharma-Test PTWS-1210 dissolution machine (Hanburg, Germany) equipped with an autosampler. The dissolution media was $\mathrm{pH} 1.2 \mathrm{HCl}$ according to "Registration specification for finished product". Dissolution media were maintained at $37 \pm 0.5^{\circ} \mathrm{C}$ and paddle speed was $100 \mathrm{rpm}$. Samples were filtered through a $40 \mathrm{~mm}$ filter and taken at $0,1,2,4,6,10,14$, and $18 \mathrm{~h}$. Six samples at each time point were analyzed by HPLC.

\section{HPLC analysis}

Alfusozin $\mathrm{HCl}$ release was detected by a Beckman HPLC system (Fullerton, USA), consisting of a UV detector (168), C18 column (4.6×120 mm, $5 \mu \mathrm{m}$, Waters), pump (126), autosampler (508), column oven (234), and data processor (Karat 32). The analysis method was modified from Alfuzosin $\mathrm{HCl}$ (USP 32-NF 27). Briefly, the wavelength of UV detector was $254 \mathrm{~nm}$, column temperature was maintained at $30^{\circ} \mathrm{C}$, the flow rate was $1.0 \mathrm{~mL} / \mathrm{min}$, and injection volume was $20 \mu \mathrm{L}$. The mobile phase was sodium perchlorate:acetonitrile:tetrahydrofuran $=80: 20: 1(\mathrm{v} / \mathrm{v} / \mathrm{v})$. Sodium perchlorate was made by adding perchloric acid $(6 \mathrm{~mL})$ to distilled water $(900 \mathrm{~mL})$, adjusted to $\mathrm{pH} 3.5$ with sodium hydroxide, and made to a final total volume of $1000 \mathrm{~mL}$ by adding additional water.

\section{Data analysis}

To analyze the in vitro release data various kinetic models were used to describe the release kinetics. The zero order rate Eq. (1) describes the systems where the drug release rate is independent of its concentration (Hadjiioannou et al., 1993). The first order Eq. (2) describes the release from system where release rate is concentration dependent (Bourne, 2002). Higuchi (1693) described the release of drugs from insoluble matrix as a square root of time dependent process based on Fickian diffusion Eq. (3). The Hixson-Crowell cube root law Eq. (4) describes the release from systems where there is a change in surface area and diameter of particles or tablets (Hixson and Crowell, 1931).

$$
\mathrm{C}=\mathrm{k}_{0} \mathrm{t}
$$

Where, $\mathrm{K}_{0}$ is zero-order rate constant expressed in units of concentration/time and $\mathrm{t}$ is the time.

$$
\log C=\log C_{0}-k t / 2.303
$$

Where, $\mathrm{C}_{0}$ is the initial concentration of drug and $\mathrm{K}$ is first order constant.

$$
\mathrm{Q}=\mathrm{Kt}^{1 / 2}
$$

Where, $\mathrm{K}$ is the constant reflecting the design variables of the system.

$$
\mathrm{Q}_{0}{ }^{1 / 3}-\mathrm{Q}_{\mathrm{t}}^{1 / 3}=\mathrm{K}_{\mathrm{HC}} \mathrm{t}
$$

Where, $Q_{t}$ is the amount of drug released in time $t, Q_{0}$ is the initial amount of the drug in tablet and $\mathrm{K}_{\mathrm{HC}}$ is the rate constant for Hixson-Crowell rate equation.

The following plots were made: cumulative $\%$ drug release vs. time (zero order kinetic model); log cumulative of $\%$ drug remaining vs. time (first order kinetic model); cumulative $\%$ drug release vs. square root of time (higuchi model) log cumulative $\%$ drug release vs. log time (korsmeyer model) and cube root of drug \% remaining in matrix vs. time (hixson-crowell cube root law)(Shoaib et al., 2006).

\section{Mechanism of drug release}

Korsmeyer et al (1983) derived a simple relationship which described drug release from a polymeric system Eq. (5). To find out the mechanism of drug release, first $60 \%$ drug release data was fitted in Korsmeyer-Peppas model:

$$
\mathrm{M}_{\mathrm{t}} / \mathrm{M}_{\infty}=\mathrm{kt}^{\mathrm{n}}
$$

Where $M_{t} / M_{\infty}$ is fraction of drug released at time $t, k$ is the rate constant and $\mathrm{n}$ is the release exponent. The $\mathrm{n}$ value is used to characterize different release mechanisms as given in table II for cyclindrical shaped matrices.

\section{Evaluation of dissolution data}

Tablet release profiles were compared by calculating a statistically derived mathematical parameter, similarity factor $\left(\mathrm{f}_{2}\right)$ (Costa et al., 2001; Moore et al., 1996). Fraction release data was used to normalize the percent drug release values for the labeled amount of alfuzosin $\mathrm{HCl}$ in each delivery system. The similarity factor is:

$$
f_{2}=50 \times \log \left\{\left[1+(1 / n) \sum_{j=1}^{n}\left|R_{j}-T_{j}\right|^{2}\right]^{-0.5} \times 100\right\}
$$

Where $R_{j}$ and $T_{j}$ are percent drug dissolved at each time point 
for the reference and test product, $n$ the number of dissolution sample times, and $t$ the time sample index. If the two profiles are identical, $f_{2}$ is 100 . Values of $f_{2} 50$ indicate similarity of two dissolution profiles.

\section{Swelling and erosion study}

Alfuzosin $\mathrm{HCl}$ and Xatral $\mathrm{XL}^{\circledR}$ tablets were randomly selected and weighed. We performed the dissolution test for both tablets, weighing and drying them at 1, 2, 4, 6, 8, 10, 12, 16 , and $18 \mathrm{~h}$. All swelling and erosion test were performed in triplicate. The swelling rate (weight gain) and erosion rate (weight loss) were calculated as follows (Tahara et al., 1995) .

$$
\begin{gathered}
\% \text { Weight gain }=100 \times \frac{\text { wet weight-dry weight }}{\text { dry weigght }} \\
\% \text { Weight loss }=100 \times \frac{\begin{array}{c}
\text { original weight-remaining } \\
\text { (dry)weight }
\end{array}}{\text { original weight }}
\end{gathered}
$$

\section{Measurement of NIR imaging}

Samples were hydrated using a USP apparatus II (USP 32NF 27) in a Pharma test PTWS 1210 dissolution tester. The dissolution medium was $900 \mathrm{~mL}$ of de-aerated stimulated gastric fluid at $37 \pm 0.5^{\circ} \mathrm{C}$, with paddle speed of $100 \mathrm{rpm}$. The hydrated sample was removed from the dissolution bath and deposited in a freeze dryer tube, which was immediately put into a carbon dioxide ice and methanol bath to freeze the sample. Once the condenser temperature was below $-40^{\circ} \mathrm{C}$ and the pressure below $13 \mathrm{~Pa}$ vacuum, the freeze dryer tube containing the sample was attached to a Freezone 1L (Labconco, Kansas City, MO, USA) freeze drier. Water was then removed by sublimation. The dried tablets were subsequently microtomed across the horizontal plane at the middle-point using a Leica EM Trim, to enable imaging of the core and gel layer of the tablet. A Foss Spectrum One NTS FT-NIR spectrometer and Spectrum Spotlight FT-IR Imaging system were used for imaging both formulations and Xatral $\mathrm{XL}^{\circledR}$. Images were obtained for dry tablets, as well as tablets that had been hydrated for 2,8 , and $18 \mathrm{~h}$.

\section{Results and Discussion}

\section{Dissolution study and kinetic mechanism}

Dissolution results of the four mono-layered Alfuzosin $\mathrm{HCl}$ tablets and triple-layered Xatral $\mathrm{XL}^{\circledR}$ are shown in Figure 1. Formulation I and II are over-released early because of the

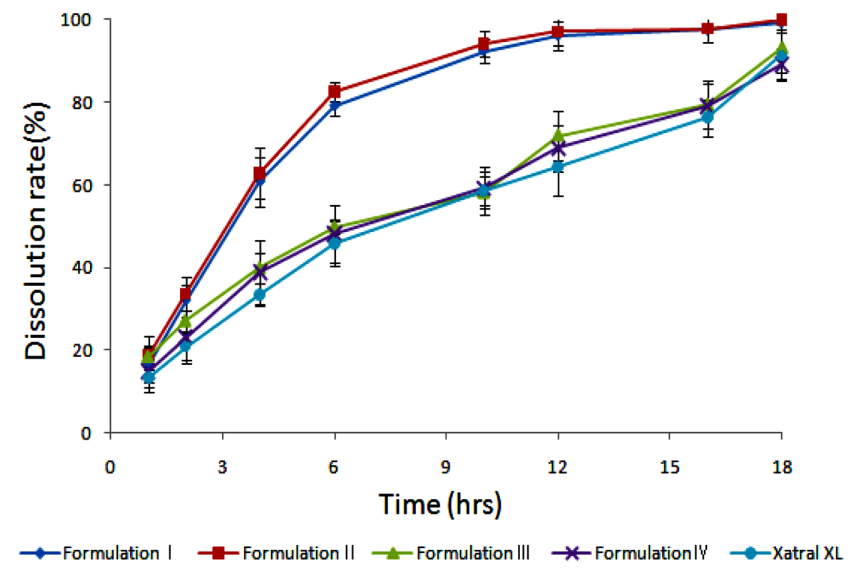

Figure 1. Comparative dissolution rate on Xatral $\mathrm{XL}^{\circledR}$ and formulation $\mathrm{I} \sim \mathrm{IV}(\mathrm{n}=6)$

Table II. Diffusion Exponent and Solute Release Mechanism for Cylindrical Shape

\begin{tabular}{cc}
\hline \hline Diffusion exponent $(\mathrm{n})$ & Overall solute diffusion mechanism \\
\hline 0.45 & Fickian diffusion \\
$0.45<\mathrm{n}<0.89$ & Anomalous (non-Fickian) diffusion \\
0.89 & Case- transport \\
$\mathrm{n}>0.89$ & Super case- transport \\
\hline
\end{tabular}

small amount of HPMC, so did not show zero-order release. However, Formulations III and IV showed similar zero-order drug release as Xatral $\mathrm{XL}^{\circledR}$ (Table III) (Vueba et al., 2004). According to the Korsmeyer-Peppas equation, all formulations and Xatral $\mathrm{XL}^{\circledR}$ showed diffusional exponent values $(n)$ ranging from 0.54 to 0.64 , indicating that the release mechanism of alfuzosin $\mathrm{HCl}$ from these matrices is anomalous (non-Fickian) transport, suggesting that both dissolution of the drug in the hydrated matrix and its own erosion modulate drug release. For Formulation III and IV and Xatral $\mathrm{XL}^{\circledR}$, the zero-order kinetic model and Higuchi's model yielded good fits $\left(\mathrm{R}^{2}>0.97\right)$.

\section{Similarity factor}

Although Formulations III and IV and Xatral XL ${ }^{\circledR}$ showed similar dissolution rates, we quantitated this similarity using the $f_{2}$ value from equation (1). $f_{2}$ values for Formulations I and II were 30.4 and 29.1, respectively, indicating different drug releas profiles. Formulations III and IV had $\mathrm{f}_{2}$ scores of 81.4 and 79.0, respectively, indicating similar dissolution to Xatral $\mathrm{XL}^{\circledR}$. As shown in Table IV, $\mathrm{f}_{2}$ values are calculated in dissolution rates based on the interval time stated in equation (1).

\section{Swelling and erosion behavior}

Formulation III showed a high $\mathrm{f}_{2}$ score and was chosen to 
Table III. Fitting of the Experimental Alfuzosin HCl Release Data to Different Kinetic Equations

\begin{tabular}{|c|c|c|c|c|c|c|c|c|c|c|c|}
\hline \multirow{2}{*}{ Formulation } & \multicolumn{2}{|c|}{ Zero-order } & \multicolumn{2}{|c|}{ First-order } & \multicolumn{2}{|c|}{ Higuchi } & \multicolumn{2}{|c|}{ "Hixson-Crowell } & \multicolumn{3}{|c|}{ Korsmeyer-Peppas } \\
\hline & $K_{0}$ & $R^{2}$ & $\overline{K_{1}}$ & $R^{2}$ & $K_{H}$ & $R^{2}$ & $K_{H C}$ & $R^{2}$ & $K_{K P}$ & $n$ & $R^{2}$ \\
\hline Formulation I & 4.451 & 0.784 & -0.083 & 0.650 & 26.279 & 0.899 & -0.102 & 0.700 & 0.201 & 0.609 & 0.853 \\
\hline Formulation II & 4.344 & 0.764 & -0.078 & 0.645 & 26.721 & 0.887 & -0.097 & 0.689 & 0.230 & 0.575 & 0.847 \\
\hline Formulation III & 4.004 & 0.974 & -0.082 & 0.883 & 20.355 & 0.979 & -0.098 & 0.925 & 0.186 & 0.535 & 0.986 \\
\hline Formulation IV & 4.053 & 0.972 & -0.090 & 0.848 & 19.767 & 0.983 & -0.104 & 0.901 & 0.155 & 0.601 & 0.989 \\
\hline Xatral XL ${ }^{\circledR}$ & 4.200 & 0.978 & -0.097 & 0.886 & 19.173 & 0.960 & -0.111 & 0.918 & 0.135 & 0.644 & 0.992 \\
\hline
\end{tabular}

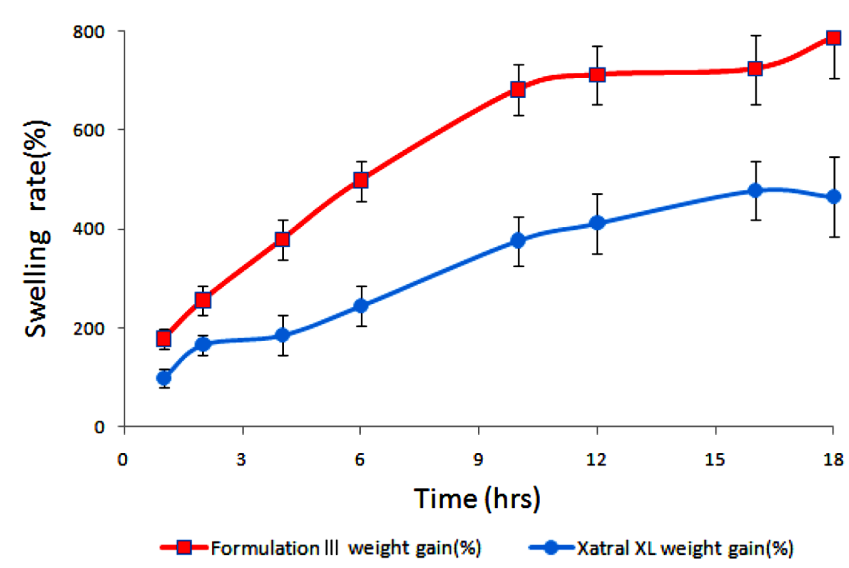

Figure 2. Swelling rate on Formulation III and Xatral $\mathrm{XL}^{\circledR}(\mathrm{n}=3)$; ( Formulation III, $(\bigcirc)$ : Xatral XL ${ }^{\circledR}$

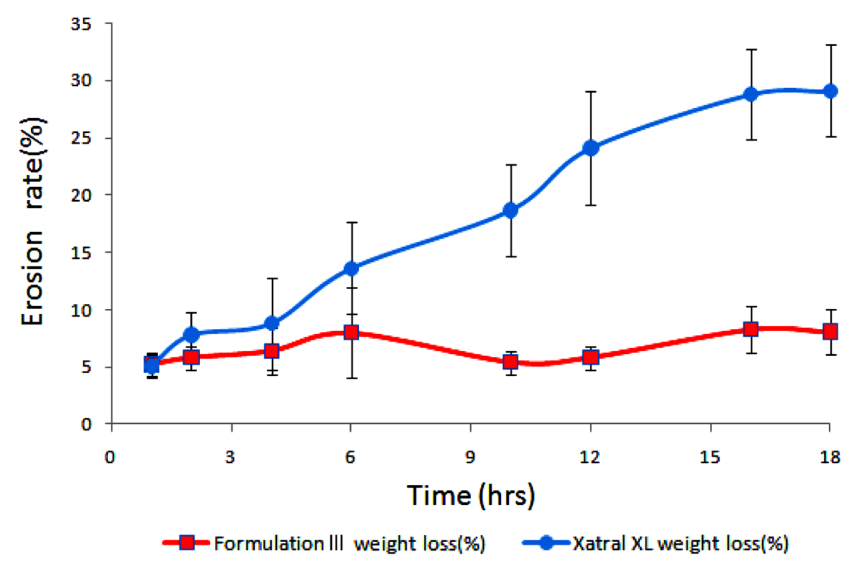

Figure 3. Erosion rate on Formulation III and Xatral $\mathrm{XL}^{\circledR}(\mathrm{n}=3)$; ( Formulation III, $(\bigcirc)$ : Xatral $\mathrm{XL}^{\circledR}$

measure swelling and erosion rates with Xatral $\mathrm{XL}^{\circledR}$. Formulation III showed dramatic increases in weight gain (Fig. 2), and both Xatral $\mathrm{XL}^{\circledR}$ and Formulation III showed increased swelling, $450 \%$ and $800 \%$, respectively, after $18 \mathrm{~h}$ (Fig. 3). Controlled drug release occurs through the absorption of dissolution fluid and swelling as erosion occurs. The erosion rate was higher for Xatral $\mathrm{XL}^{\circledR}$ than Formulation III, indicating that Xatral $\mathrm{XL}^{\circledR}$ release is governed by both swelling and erosion,
Table IV. Similarity Factor on Xatral $X L^{\circledR}$ and Formulations

\begin{tabular}{lcccc}
\hline \hline & $\begin{array}{c}\text { Formulation } \\
\text { I }\end{array}$ & $\begin{array}{c}\text { Formulation } \\
\text { II }\end{array}$ & $\begin{array}{c}\text { Formulation } \\
\text { III }\end{array}$ & $\begin{array}{c}\text { Formulation } \\
\text { IV }\end{array}$ \\
\hline $\begin{array}{l}\text { Similarity } \\
\text { factor }\left(\mathrm{f}_{2}\right)\end{array}$ & 30.4 & 29.1 & 81.4 & 79.0 \\
\hline
\end{tabular}
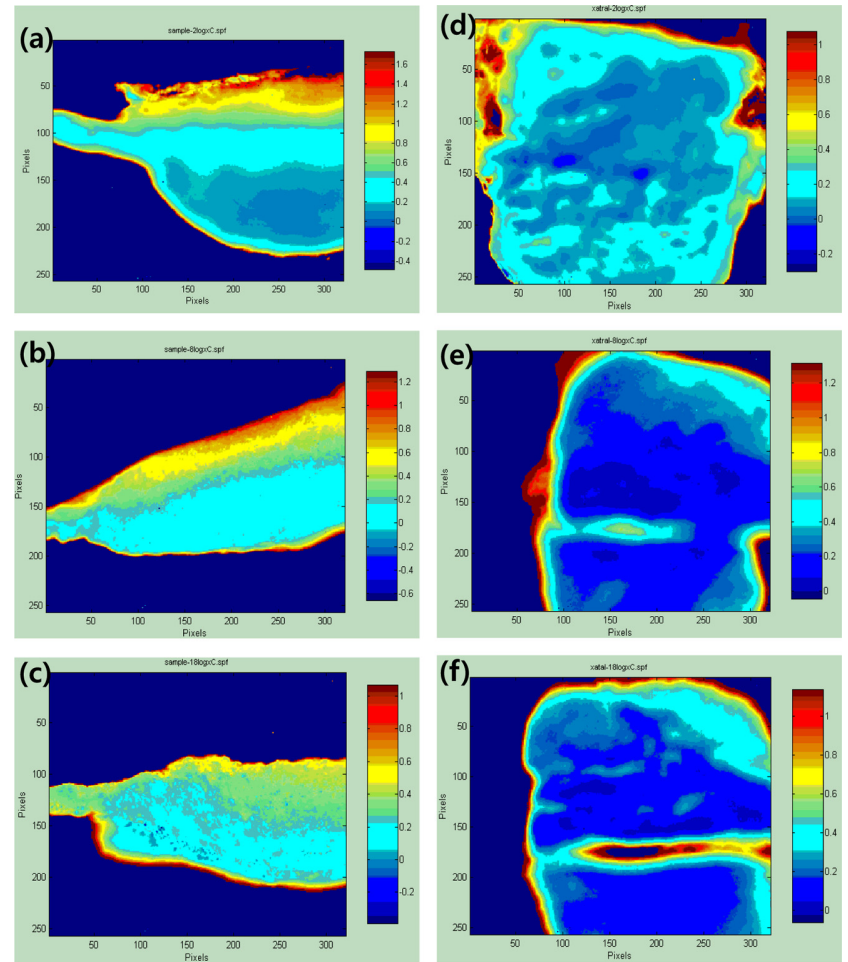

Figure 4. NIR Imaging on Formulation III and Xatral XL ${ }^{\circledR}$; (a) : after $2 \mathrm{hr}$ of dissolution on Formulation III, (b) : after $8 \mathrm{hr}$ of dissolution on Formulation III, (c) : after $18 \mathrm{hr}$ of dissolution on Formulation III, (d) : after $2 \mathrm{hr}$ of dissolution on Xatral XL ${ }^{\circledR}$, (e) : after $8 \mathrm{hr}$ of dissolution on Xatral XL ${ }^{\circledR}$, (f) : after $18 \mathrm{hr}$ of dissolution on Xatral $\mathrm{XL}^{\circledR}$

whereas Formulation III release is controlled by swelling alone.

\section{NIR Imaging}

Formulation III showed the highest $\mathrm{f}_{2}$ value and was chosen 
for NIR Imaging after 2, 8, and $18 \mathrm{~h}$ of dissolution (Fig. 4). Red areas on the images indicate tablet membranes that form hydrophilic polymers, and both Formulation III and Xatral $\mathrm{XL}^{\circledR}$ form them early, which controls drug release initially. However, by 18 h, Formulation III has maintained them hydrophilic polymer membrane, whereas the middle layer of Xatral $\mathrm{XL}^{\circledR}$ containing alfuzosin is largely eroded.

\section{Conclusion}

We have developed a mono-layered tablet with alfuzosin, a drug for benign prostatic hyperplasia, with similar dissolution properties as Xatral $\mathrm{XL}^{\circledR}$, a triple-layered, sustained-release formulation, using a multi-matrix of HPMC and PVP-k90. In particular, Formulation III showed an $\mathrm{f}_{2}$ value of 81.4 , similar to Xatral $\mathrm{XL}^{\circledR}$. Formulation III, which is easily produced by direct compression with mixed hydrophilic polymers, has potential for cheaper and more efficient manufacturing than Xatral $\mathrm{XL}^{\circledR}$.

\section{References}

Bourne DWA, 2002. Pharmacokinetics. In: Banker G.S., Rhodes C.T., Modern Pharmaceutics, $4^{\text {th }}$ ed., marcel Dekker Inc., New York, 67-92.

Buzelin, J.M., Hebert, M., Blondin, P., te Prazalf Group, 1993. Alpha blocking treatment with alfuzosin in symptomatic benign prostatic hyperplasia: comparative study with prazosin, Br. J. Urol. 72, 922-927.

Costa, P., Lobo, J., 2001. Modeling and comparison of dissolution profile, Eur. J. Pharm. 13, 123-133.

Hadjiioannou, T.P., Christian, G.D., Koupparis, M.A., Macheras, P.E., 1993. Quantitative Calculations in Pharmaceutical Practice and Reserarch, VCH Publishers inc., New York, 345-348.

Higuchi, T., 1963. Mechanism of sustained action medication. Theoretical analysis of rate of release of solid drugs dispersed in solid matrices. J. Pharm.Sci., 52, 1145-1149.
Hixson, A.W., Crowell, J.H., 1931. Dependence of reaction velocity upon surface and agitation (I) theoretical consideration. Ind. Eng. Chem., 23, 923-931.

Jardin, A.H., Bensadoun, H., Delauche-Cavaller, M.C., Attali, P., The BPH-ALF Group, 1993. Long term treatment of benign prostatic hypertropy with alfuzosin: a 12-18 month assessment. Br. J. Urol., 72, 615-620.

Jardin, A.H., Bensadoun, H., Delauche-Cavaller, M.C., Attali, P., The BPH-ALF Group, 1999. Long term treatment of benign prostatic hypertropy with alfuzosin: a 24-30 month survey. Br. J. Urol. 74, 579-584.

Jardin, A.H., Bensadoun, H., Delauche-Cavaller, M.C.., Attali, P., The BPH-ALF Group, 1991. Alfuzosin for treatment of benign prostatic hypertrophy. Lancet 337, 1457-1461.

JENN-CHIANG MACHINERY Homepage http://www.jcmco.com.tw/ dh.htm

Korsmeyer, R.W., Gurny, R., Doelker, E., Buri, P., Peppas, N.A., 1983. Mechanisms of solute release from porous hydrophilic polymers. Int. J. pharm., 15, 25-35.

Maggi, L., Conte, U., Grenier, P., Vergnault, G., Dufour, A., Jarreau, F.X., Rauch-Desant, C., 2000. Tablet with controlled release of alfuzosine chlorhydrate, US Patent 6, 149,940.

Moore, J.W., Flanner, H.H., 1996. Mathematical comparison of dissolution profile, Pharm. Tech. 20, 64-74.

Shoaib, M.H., Tazeen, J., Merchant, H.A., Yousuf, R.I., 2006. Evaluation of drug release kinetics from Ibuprofen matrix tablet using HPMC. Pak. J. Pharm. Sci., 19, 119-124.

Tahara, K., Yamamoto, K., Nishihata, T., 1995. Overall mechanism behind matrix sustained release (SR) tablet prepared with hydroxypropyl methylcellulose 2910, J. Control. Release 35, 59-66.

Teillac, P., Delauche-Cavallier, M.C., Attali, P., The Dualf Group, 1992. Urinary flow assessment after a single oral administration of alfuzosin, a new alphal, blocker, in patients with benign prostatic hypertrophy, Br. J. Urol. 70, 58-64.

Vueba, M.L., Batista, de Carvalho, L.A.E., Veiga, F., Sousa, J.J., Pina, M.E., 2004. Influence of cellulose ether polymers on ketoprofen release from hydrophilic matrix tablets, Eur. J. Pharm. Biopharm. 58, 51-59. 